\title{
INFLUENCE OF CURVED WEB CLOSED STEEL SECTIONS IN BRIDGE DESIGN
}

\author{
GILLES VAN STAEN, HANS DE BACKER, and PHILIPPE VAN BOGAERT \\ Dept of Civil Engineering, Ghent University, Ghent, Belgium
}

\begin{abstract}
A bridge is nowadays more than a structure that connects people over an obstacle. When a bridge has to be built in an urban area, either it has to be a landmark or it should blend away in the environment. The use of curved steel panels is one option to obtain these requirements. However, due to a lack of knowledge, engineers end up with a conservative design to implement these structural elements. For that reason, a Finite Element Model is made of a railway bridge, where the outer webs of the main girders have a varying web curvature. Six different models are made and compared. The most important parameters that are compared are the deformations and the stresses in the webs. The study finds that curved webs have an equal or even better behavior than flat webs, even with smaller web thickness. This makes that designers can use curved webs in their design, without needing extra steel to make their design safe.
\end{abstract}

Keywords: Railway bridge, Buckling, Stress, Plates, FEM, Eurocode, Deformation.

\section{INTRODUCTION}

Through the centuries, the design of bridges has evolved a lot from using more efficient materials, to changing the purpose of it. A bridge is nowadays more than a structure that connects people over an obstacle. When a bridge has to be built in an urban area, either it has to be a landmark or it should blend away in the environment. The use of curved steel panels is one option to obtain these requirements. Examples of the implementation of these elements are a railway bridge in Zemst (Van Bogaert 2010) and a bicycle bridge in Bruges (Flour 2012), both in Belgium (Figure $1)$.

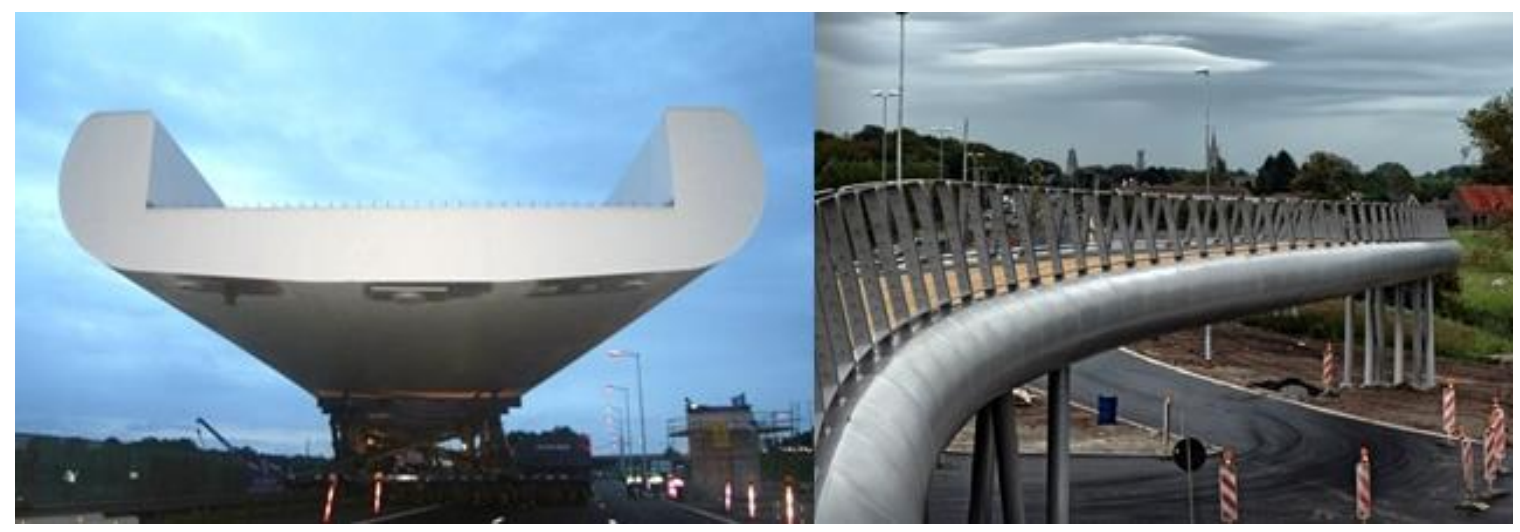

Figure 1. Railway bridge in Zemst and bicycle bridge in Bruges. 
Due to a lack of knowledge about curved webs suitable for bridge design, the examples in Figure 1 ended up with a rather conservative design. However, research is done on the buckling behavior of such panels as an isolated element (Batdorf et al. 1947, Featherstone 2003). These investigations are done for aerospace engineering purposes and thus made use of very thin steel plates of only a few millimeters, which is rather small for bridge design. Van Bogaert (2014) and Mozhdeh et al. (2011) expended the research towards bridge design with using curved webs either in a box section or by comparing the finite element approach with the theoretical formulas.

Curved panels do not only affect bridges on a local level, but also have an influence on the general bridge behavior. In order to find this influence, a typical railway bridge in Belgium is modified in such a way that the webs of the boxes of the main girder have a varying curvature radius. These curvature radii are based on previous research (Van Bogaert 2014) and exist in six different steps between a flat plate and an almost perfect cylindrical plate.

The influence of the modified webs is verified by several parameters. The first one is the deflection of the main girder under the serviceability limit state combination of only live loads. Next to that, the stress along the main girder in ultimate limit state in the webs is compared for each radius with each other. The last parameter that is compared is the web thickness of the most curved model in order to have an equal amount of steel use as for the model with flat webs.

\section{FINITE ELEMENT MODELLING OF ARCH BRIDGE}

\subsection{Model Description}

A finite element model of the Schaarbeek railway bridge, which is visible in Figure 2, is used as the basics in order to find the influence of curved web panels on the structural behavior of the arches and the main girders. The bridge is part of a high-speed railway that is connecting Brussels and Leuven, and equals a span of $140 \mathrm{~m}$ while crossing other railway tracks. The arch has a height of $22.36 \mathrm{~m}$ and is connected to the deck with 20 inclined hangers at each arch. The deck has a width of $10.5 \mathrm{~m}$ and is an orthotropic steel deck, carrying two railway tracks. The cross-sections of the arch and the main girder are shaped as rectangular boxes and the girder will have varying web curvatures as main parameter for this research, whereof only the outer web will vary. At the bottom of Figure 3 are the cross section with a flat web and the most curved web visible. Furthermore, the bridge is supported by neoprene bearings.

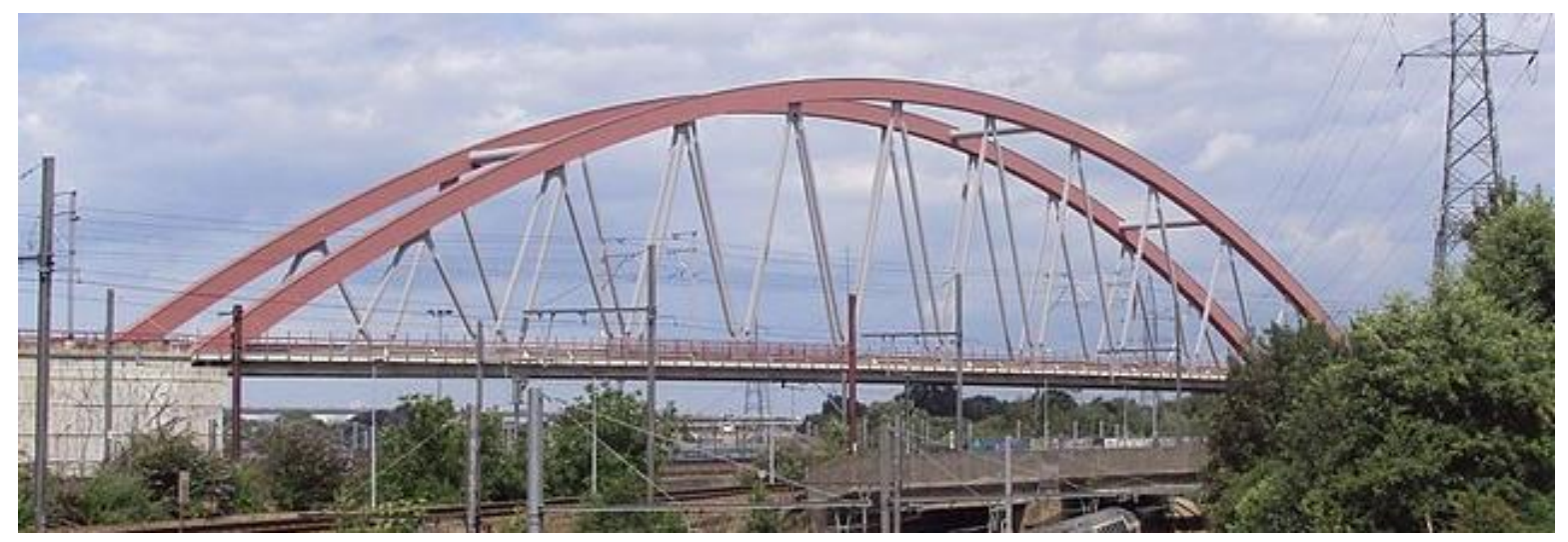

Figure 2. Schaarbeek railway bridge with span of $140 \mathrm{~m}$. 
In order to find the influence of the varying webs curvatures, the finite element model is kept as simple as possible. Therefore, a beam-plate model is created in Scia Engineer (NEMETSCHEK 2018). The software makes it easy to combine the loads, as described in the Eurocode, and to modify the properties of the bridge. A disadvantage is that at the intersecting points between plate elements and beam elements peak stresses can occur, due to different degrees of freedom the elements have. However, these are encountered by the use of averaging strips, which covers the area the beam and the plate does have in common.

All elements of interest for this paper are modelled as plate elements. This includes the box for the arches and the box for the main girders. Next to that, the hangers are connected to the box's flanges with the use of plate elements, as visible in Figure 3. At last, all internal stiffeners are plate elements as well. These are placed in the main girders at the locations where a cross beam is located and in the arches at the locations where a hanger is connecting with the box. All other elements, which are the hangers, the crossbeams and the wind bracings, are modeled as beam elements. A mesh size of $0.2 \mathrm{~m}$ is used for all elements.

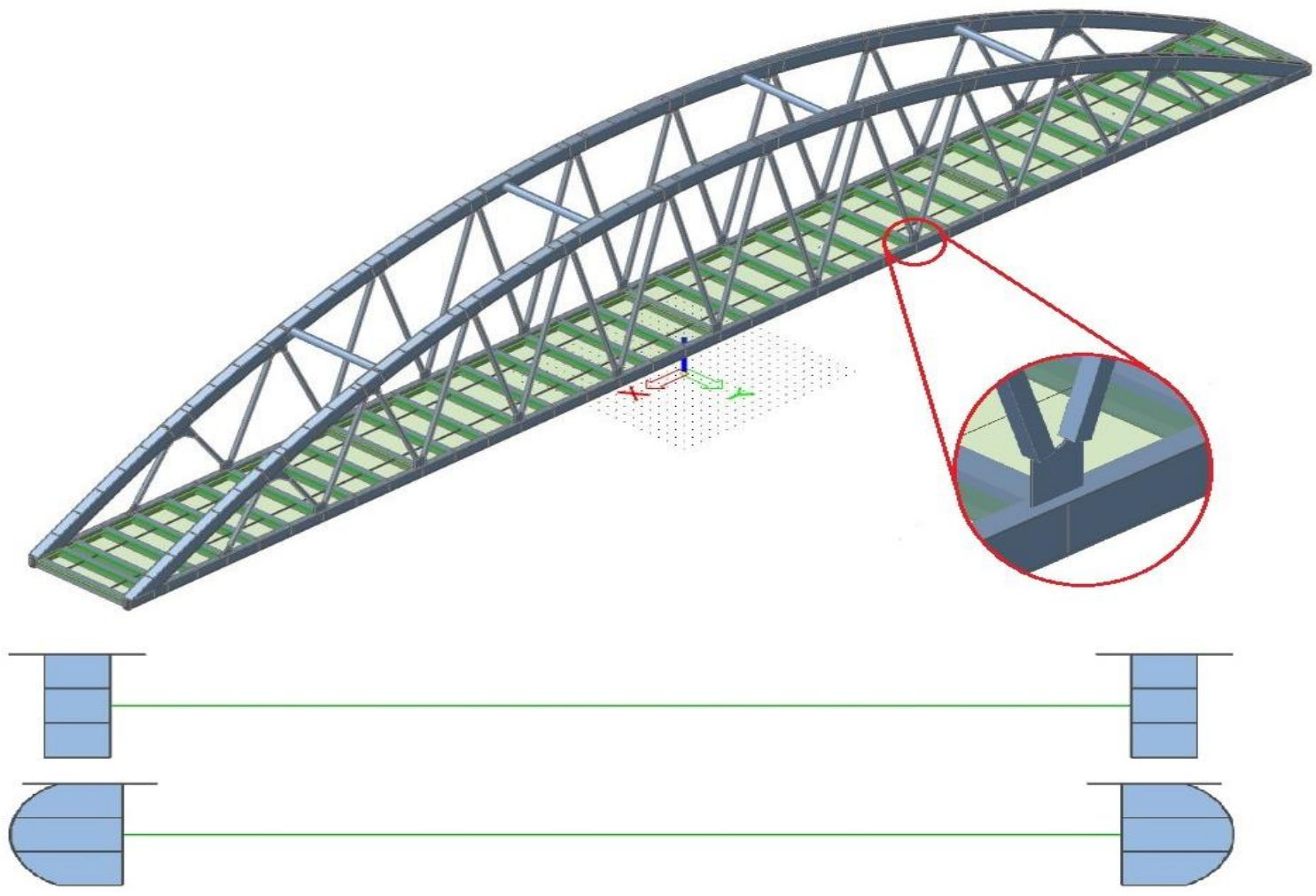

Figure 3. Finite element model of bridge and cross-section of the main girders.

The basic model with straight webs is verified with a comparison of previous research on the same bridge. De Backer et al. (2014) used the Schaarbeek bridge in order to find the critical normal force that leads to out-of-plane buckling of the arch. However, the bridge was modelled in detail; it is possible to compare the results. The detailed model gave a normal force of 13,500 $\mathrm{kN}$ for the dead loads. This simplified model in the Scia software returns a normal force of $11,900 \mathrm{kN}$ for the dead loads. Despite of this small difference, the behavior of both bridges is similar. 


\subsection{Loads}

\subsubsection{Self-weight and permanent load}

The self-weight of the bridge is generated by the software itself, while the ballast on which the railways supports is accounted with a mass density of $17 \mathrm{kN} / \mathrm{m}^{3}$ with a height of $0.6 \mathrm{~m}$.

\subsubsection{Train load model 71 (EN1991-2)}

Load model 71 from Eurocode EN 1991-2 (2003) is applied on the bridge. The combination of point loads and line loads is placed over the full span and half span of the bridge, with the point loads in the middle of the loaded field. The bridge has a double railway track, which is loaded together and separately. The loads are multiplied with the factor $\alpha$, which is taken as 1.33 since this value is recommended for international railway traffic.

\subsubsection{Wind load}

Eurocode EN 1991-1-4 (2003) describes the loads due to wind on a structure. Chapter 8 describes the loading on a bridge structure. For the wind load transverse on the structure, a simplified method is chosen as described in the code. For the wind load in the z-direction, this value has to be multiplied with a factor of 0.90 .

\section{INFLUENCE OF CURVATURE}

The basic model is modified in such a way that the moment of inertia increases, especially around the z-axis of the cross-section. It also implies the use of an extra amount of steel, which increase the dead weight of the bridge. To compare the behavior of the different web configurations, the first three fields are ignored. This is because due to the model simplification, the first fields have to be stiffened to create a stiff base for the transverse stiffness of the arch. With this in mind, the deformation of the girders due to live loads and the stresses along the girder are studied.

\subsection{Girder Deformation}

The deformation of a bridge tells a lot about the structural behavior of the structure. Table 1 gives the deformation values for the main girder in $\mathrm{z}$ - and $\mathrm{y}$ - direction. As one can expect, the reduced deformation is relatively higher in the transvers direction, due to the larger stiffness of the curved beam. However, these differences are all quite small because the global deformation is mostly determined by the arch stiffness.

Table 1. Deformation of main girder.

\begin{tabular}{ccc}
\hline Curvature ratio r/h & $\mathbf{U z}(\mathbf{m m})$ & $\mathbf{U y}(\mathbf{m m})$ \\
\hline 1500 & 80 & 13.6 \\
3 & 79.9 & 13.5 \\
1.667 & 79.9 & 13.4 \\
1 & 79.7 & 13.3 \\
0.7 & 79.6 & 13.1 \\
0.55 & 79.2 & 12.7 \\
\hline
\end{tabular}

This additional stiffness also influences the out of plane buckling behavior of the arches. The critical buckling factor increases with increasing web curvature. For the model with a curvature ratio of $\mathrm{r} / \mathrm{h}$ equal to 1.667 , the buckling factor increases from 1.27 to 1.28 (for all loads in ULS). 
This indicates that the critical buckling load increases with a few hundred kilo Newton's with an increasing web curvature. The next step in the investigation is to find the influence of curving the webs of the arch, where this parameter has a direct influence on the buckling stiffness.

\subsection{Stress Variation in Web}

The design of a web plate is mostly determined by its local buckling stiffness. The stress pattern in the web and the stress magnitude both have their influences. For that reason, it is interesting to verify if the curvature changes the stress pattern or magnitude. Figure 4 gives the stress patterns of the web fields in the middle of the bridge. The rectangle in blue is the steel plate connecting the upper flange with the hanger. The figure shows the flat web above and has an increasing curvature radius while descending in the figure.

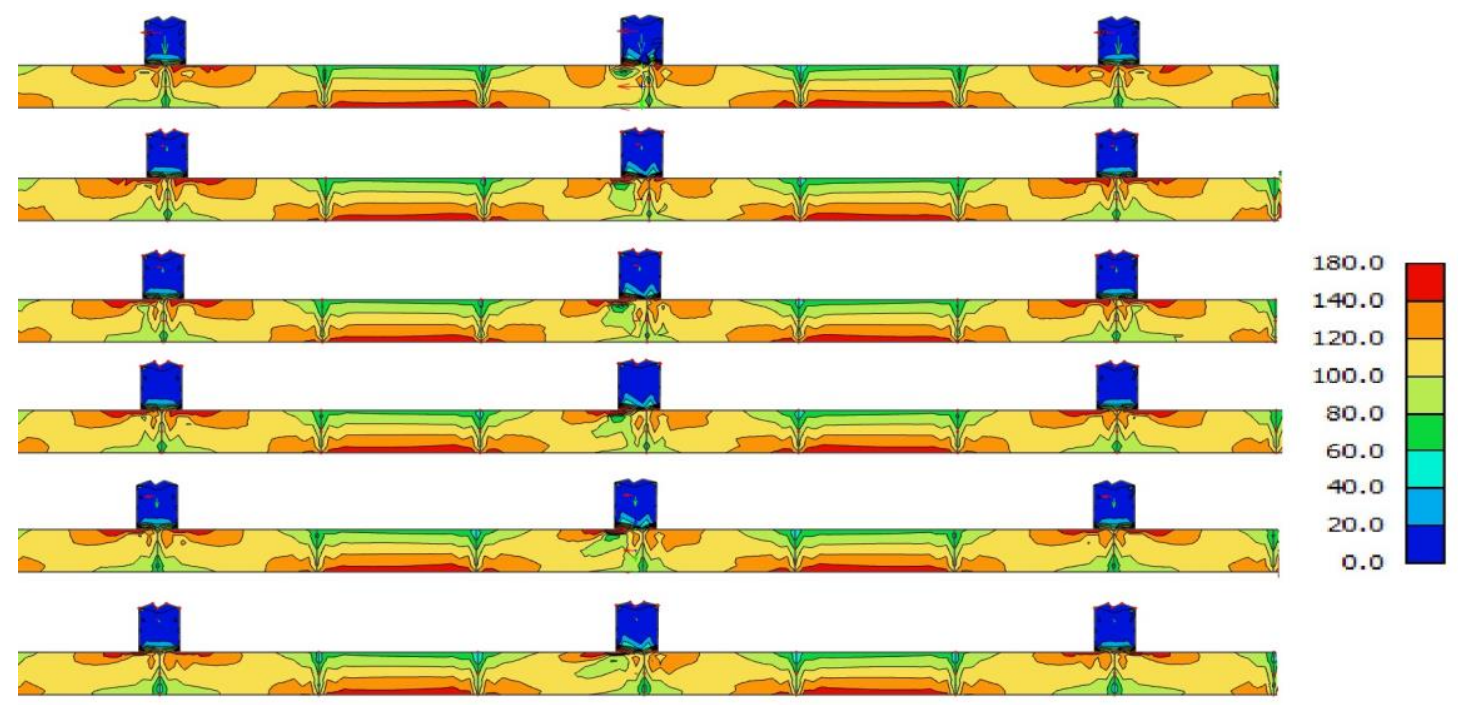

Figure 4. Stress along the girder for flat webs (above) to almost cylindrical web (down).

One can see that the stress pattern in the central web between two hangers does not change much for all models. In addition, the web fields next to the hanger supports do not change in value but has a small reduction in stress magnitude with increasing web curvature. This same behavior makes that the design procedure of a flat plate or a curved plate does not change. Next to that, Batdorf et al. (1947) found that the buckling coefficient used for the formula of the critical elastic buckling stress is increasing with increasing curvature, which makes that a curved panel can bear more stress. However, due to the thickness of $25 \mathrm{~mm}$ and a web height of $1.14 \mathrm{~m}$, the plates can be considered as stocky. This means that they will yield before buckling occurs, and thus the yield stress is of more importance.

All stresses vary between $60 \mathrm{MPa}$ and $180 \mathrm{MPa}$ in Figure 4, which is obtained by the ultimate limit state for a railway bridge, using both permanent and variable loads. This is less than the yield strength of the $\mathrm{S} 235$ steel, resulting in a safe design.

\subsection{Varying Web Thickness}

With giving the web a large curvature and the same steel thickness as a flat web, more steel is used due to the increased length of the plate. With decreasing the web thickness, the same 
amount of steel can be obtained. For the model with the most curved web, a thickness of $20 \mathrm{~mm}$ instead of $25 \mathrm{~mm}$ results in the same use of steel as the model with the straight webs.

With a smaller web thickness, the moment of inertia about both axis decrease. This is immediately seen when the deformations of the girders are checked. The deformation in $\mathrm{z}$ direction is equal with the one for the flattest web $(80 \mathrm{~mm})$. On the other hand, the deformations in the y-directions are $13.2 \mathrm{~mm}$, which is still better than most other models. Due to the increased transverse stiffness, the out of plane buckling factor is larger than for the model with the flat webs. Next to that lies the stress pattern and values in line with the ones displayed in Figure 4.

These results indicate that with a same amount of steel; equally or even better structural requirements can be reached with curved panels. This makes that designers can use curved webs in their design, without forcing the engineer into a conservative and thus expensive design.

\section{CONCLUSIONS}

A finite element model is used to find the influence of curved webs on the behavior of the bridge. A median span railway bridge in Schaarbeek is modelled and modified in such a way that the outer webs of the main girders have varying curvatures. It is found that by giving the webs a curvature and thus with increasing the moment of inertia around both axis, the bridge has an equal and even a slightly better behavior. The curved webs even increase the critical buckling factor for out-of-plane buckling of the arch. A next step in this research is modifying the webs of the arch boxes with curved webs.

In the second phase is the web thickness decreased in order to have a same amount of steel as used for the bridge with flat webs. The girder has still a better performance when the webs are curved. This makes it so the designer can use curved webs in their design, without forcing the engineer into a conservative and thus expensive design.

\section{References}

Batdorf, S. B., Stein, M., and Schildcrout, M., Critical Shear Stress of Curved Rectangular Panels. Langley Memorial Aeronautical Laboratory Langley Field, Va. Washington, 1947.

De Backer, H., Outtier, A., and Van Bogaert, Ph., Buckling Design of Steel Tied-Arch Bridges, Journal of Constructional Steel Research 103, 159-167, 2014.

Eurocode EN 1991-1-4, Actions on structures - Part 1-4: General actions - Wind actions, European Committee for Standardization CEN; Brussels, 2003.

Eurocode EN 1991-2, Actions on Structures - Part 2: Traffic Loads on Bridges, European Committee for Standardization CEN; Brussels, 2003.

Featherston, C. A., Imperfection Sensitivity of Curved Panels under Combined Compression and Shear, International Journal of Non-Linear Mechanics 38, 225-238, 2003.

Flour, P., Bicycle Bridge Brugge, 2012. Retrieved from pietflour.wordpress.com on December 2018.

Mozhdeh, A., Edlund, B. L. O., and Alinia, M. M., Buckling and Postbuckling Behaviour of Unstiffened Slender Curved Plates under Uniform Shear, Thin-Walled Structures, 49, 1017-1031, 2011.

NEMETSCHEK - Scia Engineer. Retrieved from http://help.scia.net/nl/support/dowload/scia-engineer-18 on 2018.

Van Bogaert, Ph., Design and Construction of a Double-Curved Railway Overpass and 3-Track Tubular Arch, Proc. IABSE Conference Large Structures and Infrastructures for Environmentally Constrained and Urbanised Areas, IABSE, Venice, 564-565, 2010.

Van Bogaert, Ph., Buckling Strength of Curved Bridge Girder Web Panels, Including Residual Stress, 37th IABSE Symposium, IABSE, Madrid, 58-59, 2014. 